\title{
Stationary shoulder FSW for joining high strength aluminum alloys
}

DOI:

10.1016/j.jmatprotec.2015.02.015

\section{Document Version}

Accepted author manuscript

Link to publication record in Manchester Research Explorer

\section{Citation for published version (APA):}

Wu, H., Chen, Y-C., Strong, D., \& Prangnell, P. (2015). Stationary shoulder FSW for joining high strength aluminum alloys. Journal of Materials Processing Technology, 221, 187-196.

https://doi.org/10.1016/j.jmatprotec.2015.02.015

\section{Published in:}

Journal of Materials Processing Technology

\section{Citing this paper}

Please note that where the full-text provided on Manchester Research Explorer is the Author Accepted Manuscript or Proof version this may differ from the final Published version. If citing, it is advised that you check and use the publisher's definitive version.

\section{General rights}

Copyright and moral rights for the publications made accessible in the Research Explorer are retained by the authors and/or other copyright owners and it is a condition of accessing publications that users recognise and abide by the legal requirements associated with these rights.

\section{Takedown policy}

If you believe that this document breaches copyright please refer to the University of Manchester's Takedown Procedures [http://man.ac.uk/04Y6Bo] or contact uml.scholarlycommunications@manchester.ac.uk providing relevant details, so we can investigate your claim.

\section{OPEN ACCESS}




\title{
Stationary Shoulder FSW for Joining High Strength Aluminum Alloys
}

\author{
Hao $\mathrm{Wu}^{1 \mathrm{a}}$, Ying-Chun Chen ${ }^{1 \mathrm{~b}}$, David Strong ${ }^{1 \mathrm{c}}$ and Phil Prangnell ${ }^{1 \mathrm{~d}^{*}}$ \\ ${ }^{1}$ School of Materials, University of Manchester, Manchester, M13 9PL, UK \\ ahao.wu-5@postgrad.manchester.ac.uk, byingchun.chen@manchester.ac.uk, \\ cdavid.strong@manchester.ac.uk, ${ }^{\mathrm{d}}$ philip.prangnell@manchester.ac.uk \\ ${ }^{*}$ Corresponding author
}

Keywords: Friction Stir Welding; Stationary Shoulder; Aluminium; AA7050; Thermal Modelling

\begin{abstract}
The new process of 'Stationary Shoulder' Friction Stir Welding (SSFSW) has been directly compared to conventional (Friction Stir Welding) using welds produced in a high strength AA7050T7651 aluminium aerospace alloy. The process window for each approach was first compared using torque - rotation rate decay curves. Under optimum process conditions, SSFSW had a 30\% lower heat input than FSW and the stationary shoulder resulted in narrower welds with a reduced heat affected zone (HAZ) width. The SSFSW welds also had more uniform through thickness properties and performed better than conventional FSWs in cross-weld tensile tests. In addition it is demonstrated that SSFSW process resulted in a far superior surface finish, although the stationary shoulder lead to surface 'speed cracking' under certain welding conditions. The reasons for these benefits are discussed aided by thermal and hardness modelling.
\end{abstract}




\section{Introduction}

As has been discussed in a comprehensive review by Threadgill et al. (2009), Friction Stir Welding (FSW) (originally invented by Wayne Thomas et al. at the TWI , 1991) has been subsequently widely adopted for joining aluminium alloys. Because it is a solid state joining method, FSW is particularly advantageous for welding high-strength aluminium alloys that suffer from solidification cracking and the process is therefore of considerable interest to the aerospace industry (Johnsen, 1999). In conventional FSW a single piece tool, consisting of a shoulder and probe (or pin), is rotated and plunged into the seam between two butted plates and translated. The weld metal is heated by the plastic work generated by the tool interacting with the workpiece. When the material has become sufficiently softened by the increasing temperature, because it is constrained by the tool shoulder, base plate, and surrounding colder material, it is forced to flow around the pin as the tool is translated and refills the cavity at its rear to form a joint. In the process the material within the thermomechanically affected zone (TMAZ) experiences very high strains, which results in a greatly refined grain structure within the weld 'nugget', as has been discussed by Prangnell et al. (2005). Although the material does not normally melt in FSW, the heat input generated by the tool is substantial and when welding heat-treatable aluminium alloys both residual stresses (Richards et al., 2010) and a significant heat affected zone (HAZ) are still observed (Threadgill et al., 2009).

According to the review by Neto et al. (2013), in conventional FSW between $60-80 \%$ of the heat generated by the process is produced by the tool shoulder (depending on the material thickness and tool design), with the remainder originating from the interaction of the workpiece with the smaller diameter probe. This high contribution of the shoulder to the welding power occurs because the energy dissipated by the tool is related to the tool-workpiece relative surface velocity, which increases with radius (Schmidt et al., 2004). In the standard FSW process the majority of the heat generated by the tool arises from deformation under the shoulder and is conducted down into the plate. This thus leads to a significant temperature gradient between the top and bottom surfaces of the weld. The high proportion of the heat input from the shoulder also tends to expand the HAZ at the weld crown. Colgrove et al. (2007) have further demonstrated that the heat input is limited by the maximum rotation rate before incipient melting starts to occur, which takes place first where the tool velocity is highest at the contact surface near the outer diameter of the shoulder. Hence, when welding thicker gauges, or lower conductivity materials, it is difficult to maintain a high enough temperature at the base of a weld to avoid pin failures without reducing the travel speed, which leads to a more extensive heat affected zone.

Rai et al. (2011) have reviewed progress in tool development and discuss how the FSW process has evolved to become relatively mature for aluminium welding. However, comparatively recently a 
new variant to the FSW process has been proposed by Russell et al. (2008); termed 'Stationary', Shoulder Friction Stir Welding (SSFSW), which has received surprisingly little attention in the literature. The SSFSW concept was first proposed by Russell et al. (2008) to reduce the large through-thickness temperature gradients normally seen when welding low thermal conductivity titanium alloys. In SSFSW the probe is rotated through a bearing assembly in the tool shoulder, which is fixed to the head of the welding machine (Fig. 1). During welding the non-rotating shoulder slides across the surface of the workpiece, while only the tool probe rotates within the bearing housing. In the modified process little heat is therefore produced by the shoulder as there is only a slow sliding contact and nearly all the energy originates from the plastic work provided by the probe. Because in conventional FSW the majority of the heat is generated by the rotating shoulder, and with SSFSW it is provided almost entirely by the action of the probe, FSW and SSFSW processes could thus be viewed as being analogous to the conduction and keyhole modes used in laser welding.

In principle, even when welding much more conductive materials like aluminium, the SSFSW process could still be advantageous. For example, when welding with only a probe a narrower more parallel through-thickness thermal field would be expected, which should lead to a reduced heat affected zone width, as well as lower levels of distortion. Furthermore, there are other potential benefits of SSFSW over the conventional FSW process, such as an improved surface finish (Liu et al., 2013). Using a AA6061 aluminium alloy, Widener et al. (2006) have demonstrated that with a stationary shoulder successful welds can be produced in material as thin as $3.3 \mathrm{~mm}$. It has also been noted that in SSFSW the nugget texture becomes dominated by the shear deformation induced by the pin (Davies et al., 2011). The effect of the welding parameters on the failure behaviour and hardness distribution of SSFSWs produced in an AA2219-T6 alloy has also been reported by Liu et al. (2013). In other work by Martin et al. (2011) the stationary shoulder principle has been applied to fillet welding with promising results. However, while some information has been presented at conferences (for example by Barbini et al., 2014) no systematic comparison has yet been published on the relative performance of welds produced by the FSW and SSFSW processes, so that a consensus can be reached on the preferred welding method.

In this paper we have attempted to address this knowledge gap by directly comparing welds produced by the FSW and SSFSW processes when applied to butt welding a typical aluminiumaerospace alloy (AA7050). To achieve this aim, identical tool geometries were used for each method. The respective relationships between the welding parameters and power were first assessed for both processes, so that a rational basis could be used for selecting conditions by which the two methods could be directly compared. In order to better understand the effect of using a stationary 
shoulder tool, on the heat distribution in the SSFSW welds, modelling has been employed to predict the effect of reducing the shoulder power on a weld's thermal field and hardness distribution. These simulations have then been used to help interpret the weld's local strain response, determined by digital image correlation (DIC) strain mapping in cross-weld tensile tests. We have also compared the surface quality that can be achieved by the two welding methods and note a new type of weld defect that is specific to the SSFSW process.

(a)

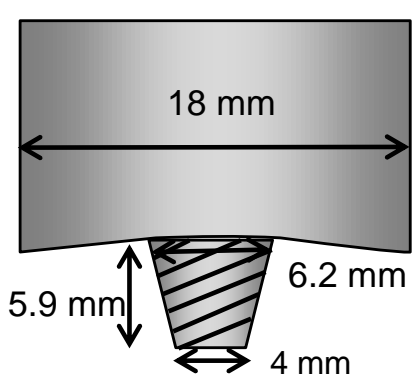

(b)

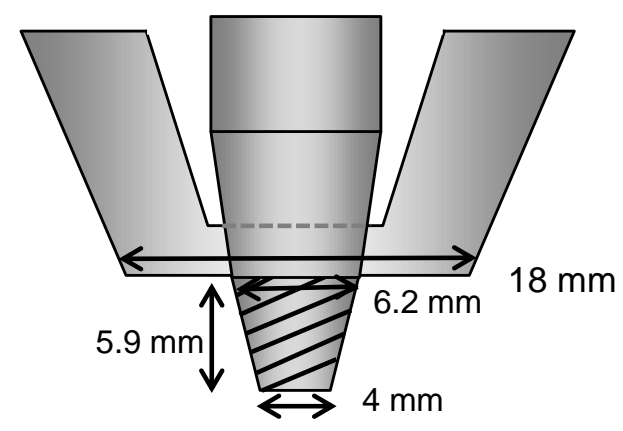

Fig. 1: Schematic diagrams of (a) the FSW and (b) the SSFSW tools used in this investigation with their dimensions.

\section{Experimental}

All the welds investigated were produced in a butt configuration, in $6.3 \mathrm{~mm}$ thick AA7050-T7651 plate, using conventional and stationery shoulder welding tools that had near-identical geometries (see Fig. 1). Both tools had a shoulder diameter of $18 \mathrm{~mm}$ and a $5.9 \mathrm{~mm}$ long conical, threaded triflat probe, with root and tip diameters of $6.2 \mathrm{~mm}$ and $4 \mathrm{~mm}$, respectively. The standard FSW tool had a slightly concave shoulder and welding was performed with a $2^{\circ}$ tilt and plunge depth of 0.2 $\mathrm{mm}$. The SSFSW tool was mounted vertically and the shoulder had a slightly convex radius to allow it to slide across the plate. During welding the torque (M) was logged from the welding machine. A parametric study was first performed with both welding methods to assess the effect of the process parameters on the welding power. This was obtained by fitting torque decay curves to measurements made with increasing rotation rate at different travel speeds, following the method proposed by Cui et al. (2010).

To analyse the effect of the different welding conditions, hardness contour maps were produced on transverse weld cross-sections using an Instron microhardness machine with a $0.5 \mathrm{~kg}$ load. The weld zones and other microstructural features were also investigated by conventional optical microscopy, following standard metallographic preparation. Grain sizes within the weld nugget 
were measured by EBSD using an FEI Sirion FEG-SEM. A $\mu$-scan SC200 laser profiler was also employed to measure the levels of surface roughness produced by the two welding methods.

The mechanical properties of the joints were characterised in cross-weld tensile tests using standard (ASTM B209) flat, $3 \mathrm{~mm}$ x $13 \mathrm{~mm}$ by $60 \mathrm{~mm}$ long gauge section, samples. The tensile samples were machined from the mid-plane of each plate. During the tensile tests, digital image correlation (DIC) was employed to map the local strain evolution across each joint. Tensile testing was performed at a nominal strain rate of $1 \mathrm{~mm} \mathrm{~min}^{-1}$. Elongation to failure was measured using a 50 mm gauge length extensometer fixed symmetrically across each weld. For the DIC measurements, a speckle pattern was first applied to the samples using a spray paint technique. To ensure consistency, all hardness and tensile tests were performed on welds that had been allowed to naturally age for two months prior to testing.

\section{Modelling}

A finite difference code TS4D, developed by Mackwood and Crafer (2005), was used to investigate the effect of systematically reducing the contribution of the heat input generated by the shoulder on the temperature distribution in FSW. The TS4D code allows multiple heat sources to be defined to represent the power input for a given welding process and solves the heat flow problem under steady state conditions. In the model a surface ring-shaped heat source was used to represent the shoulder and ten thin-slice cylindrical volume sources, with reducing diameter, were used to represent the conical probe. The power was distributed in each case in proportion to the surface velocity. For the probe, the shoulder power was increased in proportion to the radius across the ring source surface (as described by Richards et al., 2008). Standard values of thermal conductivity were used for the AA7050 alloy plate. The gross power input obtained from the machine torque was employed as a starting point to calibrate the model. To obtain more reliable predictions the heat input was then adjusted to obtain a fit to thermocouple measurements, repeated on several welds at six locations; i) as close as possible to the tool without incurring damage, near the plate top, bottom ( $1 \mathrm{~mm}$ deep) and mid plane, and ii) at distances of 10, 20, and $30 \mathrm{~mm}$ from the weld centre at the plate mid-thickness.

The local weld thermal cycles predicted by the thermal simulations, at a given position, were then used as an input to a semi-empirical hardness model. This model was originally proposed by Shercliff and Ashby (1990) and, although relatively simple, has been shown by Robson and Sullivan (2006) to be sufficiently accurate to predict the effect of changes to the thermal field on the 
hardness profiles seen across FSWs. In the model the local hardness is tracked using a 'normalised precipitate volume fraction' $\left(f / f_{0}\right)$ given by:

$$
\frac{f}{f_{0}}=\frac{H v-H v_{\min }}{H v_{\max }-H v_{\min }}
$$

which is equivalent to the fraction of hardening relative to the maximum, $H v_{\max }$, and minimum, $H v_{\min }$, hardness of the alloy, when in peak aged and fully overaged conditions, respectively. The change in $f / f_{0}$, or relative hardness, for a given time, $t^{*}$, at a temperature, $T$, is related to;

$$
t^{*}=t_{r} \exp \left[\frac{Q_{e f f}}{R}\left(\frac{1}{T}-\frac{1}{T_{r}}\right)\right]
$$

where, $\mathrm{t}_{\mathrm{r}}$ is the time for full softening to occur at a reference temperature, $T_{r} . Q_{\text {eff }}$ is the effective activation energy for the over-ageing process and $\mathrm{R}$ is the gas constant. $f / f_{0}$ can then be related to time by;

$$
\frac{f}{f_{0}}=1-\left(\frac{t}{t^{*}}\right)^{\frac{1}{2}}
$$

To account for soft impingement and particle coarsening (see Robson and Sullivan 2006) a fitted calibration master curve (developed from isothermal heat treatments at several temperatures and times) was then used to 'look up' the effective time to reach the required normalised volume fraction at a given temperature. The model can then be used to integrate the hardness change through a weld thermal cycle by tracking the level of softening that occurs for small isothermal steps, which are related to the master curve by;

$$
\frac{t}{t^{*}}=\int_{0}^{t} \frac{d t}{t^{*}}
$$

The level of hardness recovery by post-weld natural ageing was included in a second step, where the concentration of solute in solution is related to the local peak temperature reached in the weld thermal cycle, giving the final weld hardness distribution (full details can be found in Robson and Sullivan, 2006). 


\section{Results and Discussion}

\section{Comparison of the Effect of the Process Parameters on Welding Power in FSW and SSFSW}

Because in FSW the welding parameters have a large effect on the resultant joint properties (Hassan et al., 2003), it was important to adopt a methodology that allows a systematic comparison to be made between the two processes. Unfortunately this is not as simple as it first appears since, as will be seen below, the optimum process windows were quite different for the FSW and SSFSW methods and they could not therefore be compared with the same welding conditions.

In FSW the welding power, $q$, is related to the torque, $M$, by;

$$
q=M \omega
$$

where $\omega$ is the rotation rate $\left(\mathrm{rad} \mathrm{s}^{-1}\right)$. If a uniform material flow stress is assumed the torque can be simply expressed by:

$$
M=2 \pi \frac{\sigma}{\sqrt{3}}\left[\frac{1}{3}(1-\delta)\left(r_{s}^{3}-r_{p r}^{3}\right)+\left(\frac{1}{3} m^{2} h^{3}+m h^{2} r_{p t}+h r_{p t}^{2}\right)+\frac{1}{3} r_{p t}^{3}\right]
$$

Equation (6) has been adapted for a tapered pin geometry from Schmidt et al. (2004), where the first term represents the contribution from the shoulder, the second the conical probe surface, and the third the probe base. The tool dimensions $r_{s}, r_{p r}, r_{p t}$, and $h$ are the shoulder, probe root, and tip radii, and probe height, respectively, $m$ is the probe's gradient of taper, $\sigma$ is the material flow stress, and $\delta$ is a shoulder slip parameter (usually assumed to be about 0.5; see Schmidt et al., 2004, or Cui et al., 2010). In reality the torque will be affected by the material flow stress decreasing with temperature, which will occur non-uniformly across the tool surfaces. However, this simple analysis allows an upper bound estimate to be made of the relative reduction in power seen on removing the rotating shoulder term. With the tool dimensions employed in this study, welding with a stationary shoulder at the same rotation rate as for a conventional tool can therefore be expected to decrease the welding power by a maximum of $\sim 70 \%$.

The effect of the welding parameters on the actual power dissipated into the workpiece by the two alternative processes can be better compared by following the approach proposed by Cui et al. (2010) of fitting torque - rotation rate decay curves to actual welding data, using the relationship:

$$
M=\left(M_{0}-M_{\infty}\right) \exp (-n \omega)+M_{\infty}
$$

where $M_{0}$ is the theoretical torque at zero rpm, calculated from equation (6), when the material will be at room temperature and have a uniform flow stress, $M_{\infty}$, is the minimum torque at high rpm and $n$ is the decay coefficient. Using equation (5), the fitted torque curves can then be used to derive 
power curves for each process. In Fig. 2 the fitted torque and calculated power curves thus obtained are compared for FSW and SSFSW for a high, medium, and low travel speed. Encouragingly, the torque values for the traditional FSW process agree well with data from Long et al. (2007). The results in Fig. 2 confirm that for a given rotation rate and travel speed the stationary shoulder tool develops a much lower torque, and hence welding power, than the standard FSW process. With a stationary shoulder there is approximately a 70\% reduction in power at low rpm. However, this difference reduces to about $50 \%$ at high rpm, where the torque curves reach a lower limit because the material flow stress becomes very low as the temperature at the hottest points on the tools' surfaces approach the alloy's incipient melting point (Colegrove et al., 2007, Williams et al. 2006). Fig. 2(a) also shows that, as has been previously noted by Schmidt et al. (2004), the torque is more greatly affected by the rotation rate than the travel speed, although this latter parameter becomes more important at high rotation rates.

(a)

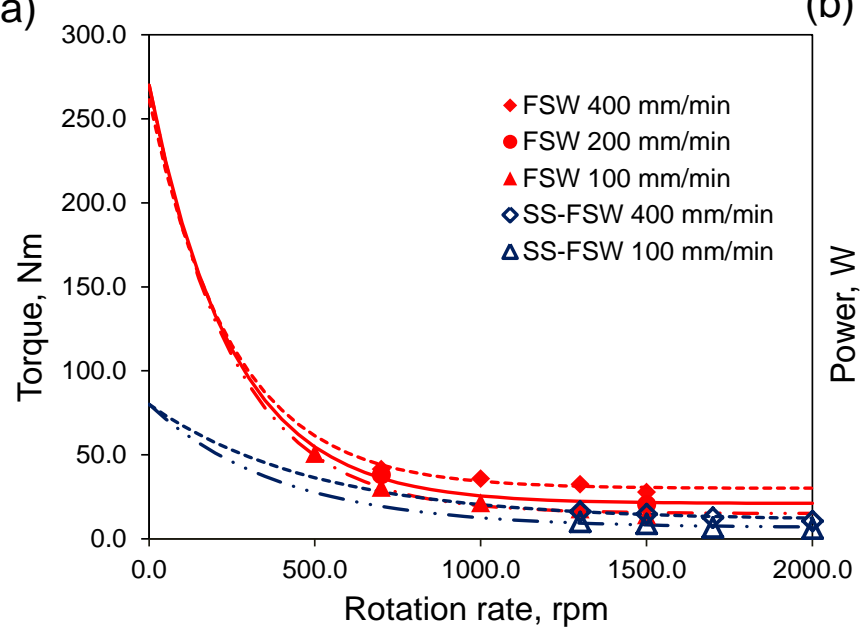

(b)

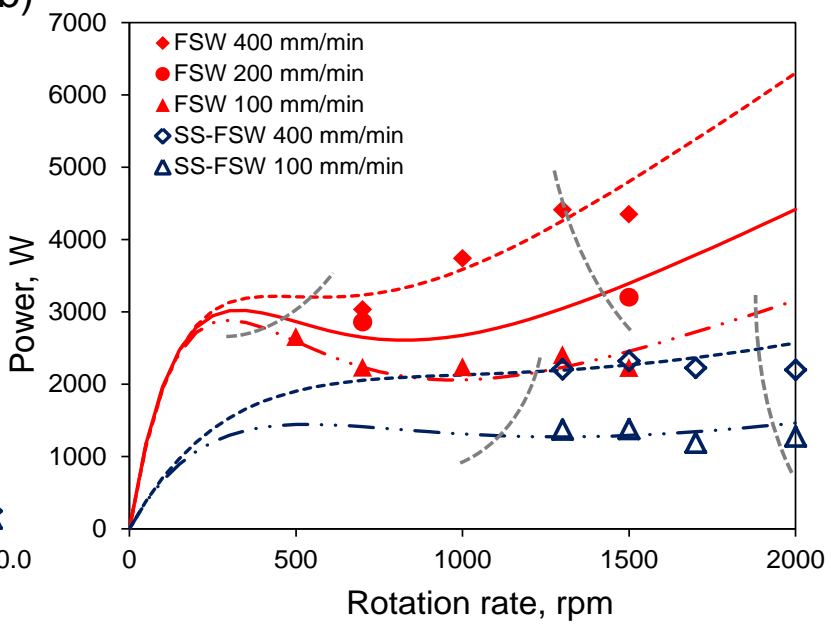

Fig. 2: (a) Measured and fitted torque - rotation rate curves and (b) the corresponding power curves derived for both process variants, following the method detailed in the text. In (b) the approximate upper and lower process boundaries are shown as short dashed curves.

The approximate upper and lower limits of the process windows for the two methods are indicated in Fig. 2(b) by vertical dashed lines. The process window boundaries were limited at high rotation rates by overheating and at low rotation rates by pin failure, caused by the high material shear strength when the welds became too cold. From Fig. 2(b) it is thus apparent that it is not sensible to compare FSW to stationary shoulder welding using the same conditions (of rotation rate and travel speed) as this produces very different heat inputs that are not optimal for each process. For example, at a particular travel speed, because the SSFSW tool produces a far lower torque a much higher rotation rate is required than would be optimum for FSW to achieve a sufficient weld temperature to 
avoid tool failures: alternatively, when FSW is carried out at a rotation rate that is optimum for SSFSW, this causes excessive heating resulting in defects arising from incipient melting under the shoulder contact and an abnormally wide HAZ.

Another option is to compare the two processes with the same welding power. However, this was again found to be unsatisfactory, as at the same travel speed the welding powers within the respective process windows did not overlap. This is primarily because the optimum process window for SSFSW was found to be shifted to around a $30 \%$ lower power than for FSW (Fig. 2b). To get into the same power range that was optimum for SSFSW, the rotation rate for FSW had therefore to be reduced to a level where the probes regularly failed. As will be discussed further below, this problem arises because of the different heat distributions developed in the two processes, and when the rotation rate for FSW is reduced to overlap with the optimum power range for stationary shoulder welding the base of the conventional welds became too cold, creating an excessive load on the pin.

To enable a valid comparison to be made between the two alternative processes, optimum welding conditions were therefore selected near the centre of their respective process windows at the highest travel speed of $400 \mathrm{~mm} \mathrm{~min}^{-1}$, as this would be expected to give the best joint performance (Threadgill et al. 2009). At this travel speed the optimum rotation rates were 1500 RPM for SSFSW and 700 RPM, and FSW. However, it should be remembered that with these conditions the stationary shoulder process had a welding power that was approximately $30 \%$ lower than for conventional FSW. To allow exploration of the effect of a wider range of conditions on the welds' HAZ profiles, additional welds were also produced where the travel speed was systematically varied from 100 to $400 \mathrm{~mm} \mathrm{~min}^{-1}$, while maintaining the same rotation rates in each case.

\section{Weld Zone Hardness Profiles}

Hardness profiles across FSWs in high strength heat-treatable Al-alloys, like AA7050, are known to be dominated by the state of matrix precipitation, which is controlled by the thermal cycle experienced at a particular location, as has been discussed by several authors, including; Kamp et al. (2006), Hassan et al. (2003), and Sullivan and Robson (2008). There are two main effects that determine the post-weld hardness distribution. During welding loss of hardness arises where the peak temperature reached is sufficient to cause over-ageing due to coarsening and, or, dissolution of the fine metastable strengthening phases (e.g. $\eta$ ' in AA7050) which, depending on the time and temperature, can be replaced by a coarser distribution of more stable equilibrium phases (e.g. $\eta$ in AA7050; Hassan et al. 2003). In addition, where the temperature reached in the weld zone rises close to, or above, the solvus temperature $\left(>480^{\circ} \mathrm{C}\right.$ in AA7050) dissolution of the equilibrium and 
strengthening phases can occur, which typically takes place in the weld nugget (Kamp et al. 2006, Hassan et al. 2003). When measured immediately after welding, this leads to a 'U'-shaped hardness profile. However, in alloys like AA7050 in the hottest region of the weld where the peak temperature approached the alloy's solvus temperature post-weld natural ageing can recover much of the strength lost during welding, as has been discussed by Kamp et al. (2006). The superposition of this effect on the hardness profile seen immediately after welding leads to a rise in hardness in the weld centre with increasing natural ageing time and the formation of a ' $W$ ' shaped hardness profile (Fig. 4). The minima positions in the profiles correspond to the locations where maximum over-ageing has occurred and are normally found near the TMAZ/HAZ boundary in FSW (see Threadgill et al., 2009; Kamp et al., 2006).

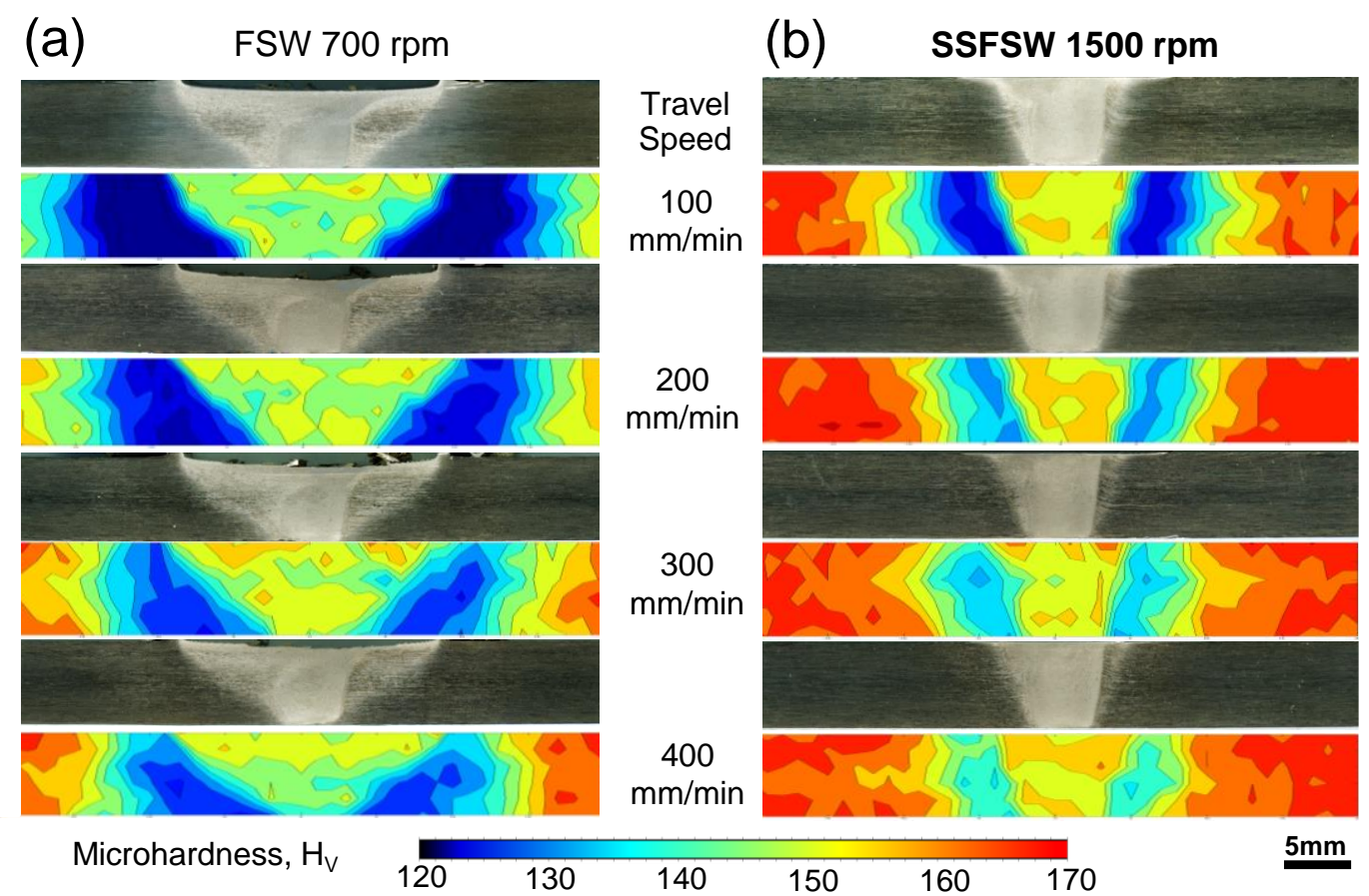

Fig. 3: Weld cross-sections and corresponding hardness contour maps from welds produced by both processes at comparable optimum rotation rates with increasing travel speed, (a) a FSW at $700 \mathrm{rpm}$ and (b) SSFSW at 1,500 rpm, measured after two months post-weld natural ageing.

In Fig. 3 transverse cross-section hardness contour maps are compared from welds produced with the FSW and SSFSW methods under the optimum conditions, of 700 and $1500 \mathrm{rpm}$ at $400 \mathrm{~mm} \mathrm{~min}$ 1 , and with lower travel speeds. The hardness maps were measured 2 months after welding to allow a consistent level of natural ageing. Corresponding hardness profiles across the mid-plane of each weld are also shown in Fig. 4, which all have the characteristic ' $W$ ' shape, discussed above. With both welding methods, increasing the travel speed results in the HAZ reducing in width and the 
hardness minima becoming less deep. As has been previously discussed by Kamp et al. (2006) and Williams et al. (2006) this occurs because when the speed increases the thermal field shrinks closer to the tool and the material in the HAZ experiences a more rapid thermal cycle, which reduces the extent of over-ageing.

(a)

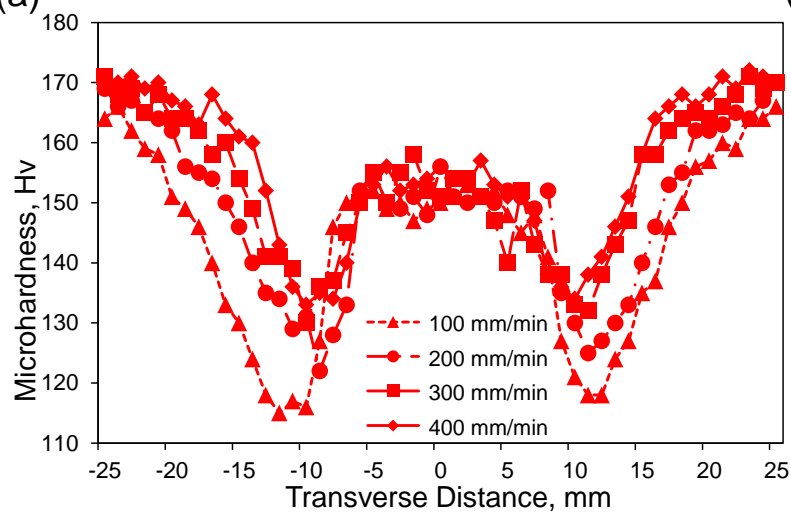

(b)

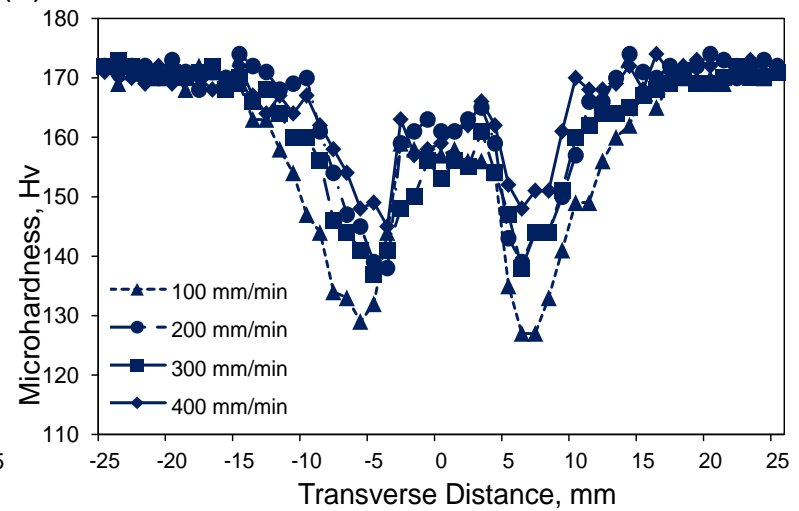

Fig. 4: Mid-plane hardness profiles obtained from welds produced with increasing travel speeds at optimum rotation rates; (a) a FSW tool at $700 \mathrm{rpm}$ and (b) a SSFSW tool at 1,500 rpm, measured after post-weld natural ageing for two months.

(a)

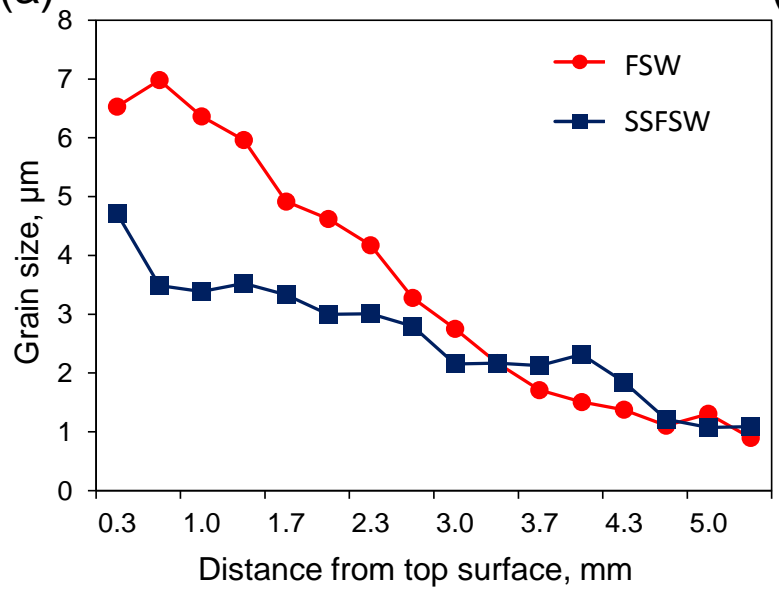

(b)

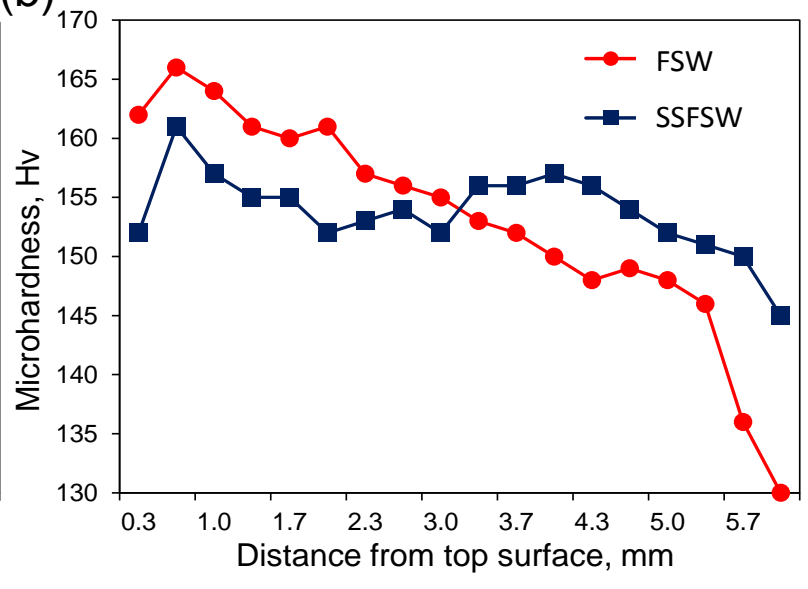

Fig. 5: Typical through-thickness (a) grain size and (b) hardness levels, seen for the FSW and SSFSW processes, plotted down the centre of a weld nugget, from welds produced under optimum conditions of $700 \mathrm{rpm}$ and $1500 \mathrm{rpm}$, at $400 \mathrm{~mm} / \mathrm{min}$, respectively.

Overall, it can be clearly seen that in the stationary shoulder process, where the welding energy was generated only by the action of the probe, the absence of shoulder rotation narrows the thermal field at the top surface and the minimum hardness contours move closer together and become more vertical through the plate thickness. For example, in Fig. 3 and 4 the HAZs for the standard FSW 
welds are consistently wider than for the SSFSW process, particularly near the top surface, and at the mid-section depth (Fig. 4) the HAZ width was reduced by approximately $40 \%$ in the stationary shoulder welds.

In addition to decreasing the HAZ width, the hardness maps in Fig. 4 indicate that microstructural variation is reduced through the plate thickness with the SSFSW process. This can be seen more clearly in Fig. 5, where weld centreline through-thickness hardness and nugget grain size values are compared. From Fig. 5 it is evident that the through-thickness hardness and grain size gradients (Hassan et al., 2003) are substantially lower in the stationary shoulder welds. This presumably occurs because when heat is generated solely by the pin there is a more uniform though-thickness temperature distribution. However, it is apparent from Fig. 5 that welding with a stationary shoulder does not completely eliminate through-thickness property variation. This can be attributed partly to the use of a conical pin profile, which will generate more heat at the top of the weld, but also important is the role of the backing plate which causes a greater rate of heat loss at the weld root.

\section{Surface finish}

A potential advantage of welding with a stationary shoulder is the superior surface finish it can produce, as has been reported by Liu et al. (2013). In the normal FSW process translation of the rotating shoulder generally creates some flash and leaves regular semi-circular marks on the surface related to the welding pitch (Threadgill et al., 2009). In the present study surface quality was investigated using a $\mu$-scan SC200 laser profiler with a resolution of $40 \mu \mathrm{m}$. Results from these measurements are shown in Fig. 6, along with examples of surface height deviation maps.

It can be seen form Fig. $6 \mathrm{c}$ that with a stationary shoulder the surface roughness parameter, Ra, was reduced by over an order of magnitude compared to that seen with the conventional friction stir weld. This far smoother surface results from the ironing effect of sliding a non-rotating shoulder across the weld surface. In addition in the stationary shoulder welds the reduction in plate thickness normally seen along the weld centre line after FSW was also substantially reduced; from $\sim 1 \mathrm{~mm}$ to less than $0.2 \mathrm{~mm}$ (Fig. 6d). This virtual elimination of the reduction in weld member thickness normally seen in friction stir welding is an important benefit if a weld is to be deployed in service without further machining and results from a dramatic decrease in the shoulder plunge depth. This improvement occurs with the stationary shoulder tool because it does not heat the part surface and therefore the downforce is more easily supported by the colder material surrounding the narrower hot deformation zone around the pin. This means that an SSFSW tool can be used with a high downforce without the shoulder sinking excessively into the plate. 
(a)

(c)
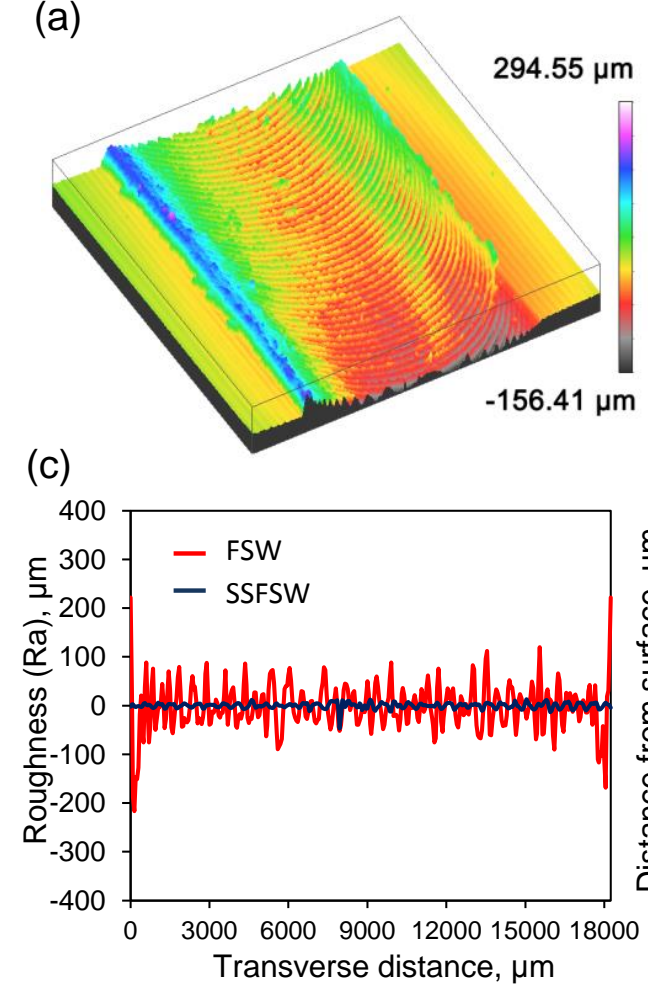

(b)

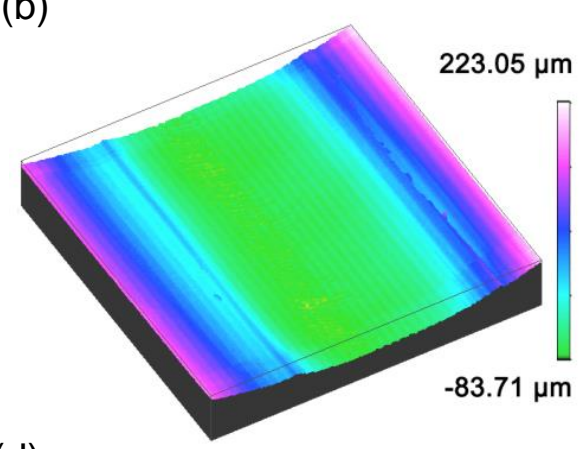

(d)

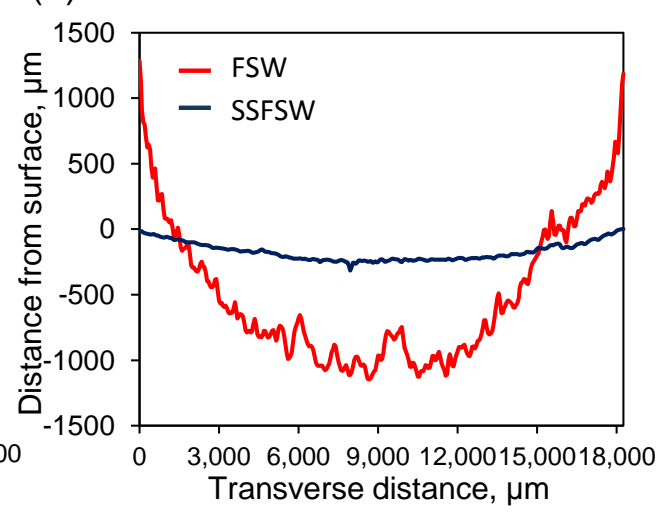

Fig. 6: Comparison of the surface quality obtained with both processes; (a) and (b) surface displacement maps for FSW and SSFSW, respectively, (c) and (d) the surface roughness (Ra) and the local displacement relative to the original plate surface, measured across each weld track, for welds produced under optimum conditions (FSW $700 \mathrm{rpm}, 400 \mathrm{~mm} / \mathrm{min}$ and SSFSW $1500 \mathrm{rpm}$, $\left.400 \mathrm{~mm} \mathrm{~min}^{-1}\right)$.

In contrast to the improvements noted above, a negative aspect of welding with a stationary shoulder was also found in this study. Small surface cracks were seen when using hotter welding conditions, examples of which are shown in Fig. 7, along with a graph depicting their average depth as a function of rotation rate at a travel speed of $400 \mathrm{~mm} / \mathrm{min}$. These flaws were regularly spaced down the centreline of the area swept by the shoulder. From Fig. 7a it can be seen that they are similar in appearance to 'speed cracks' described by Peng and Sheppard (2004) that can arise when extruding aluminium. Such cracks are known to be a particular problem in alloys with a wide freezing range and form due to the material becoming over heated and sticking to the die surface. Confirmation of the origin of the flaws can be seen in the magnified insert in Fig. 7b, which shows evidence of tearing associated with grain boundary liquation. It is also evident from Fig. $7 \mathrm{~b}$ that the cracks can be eliminated by reducing the weld temperature through lowering the pin rotation rate and a similar improvement was found by decreasing the travel speed. Subsequent to this study, we 
have also been able to expand the welding conditions that avoid surface cracking by using a low friction coating on the tool shoulder.
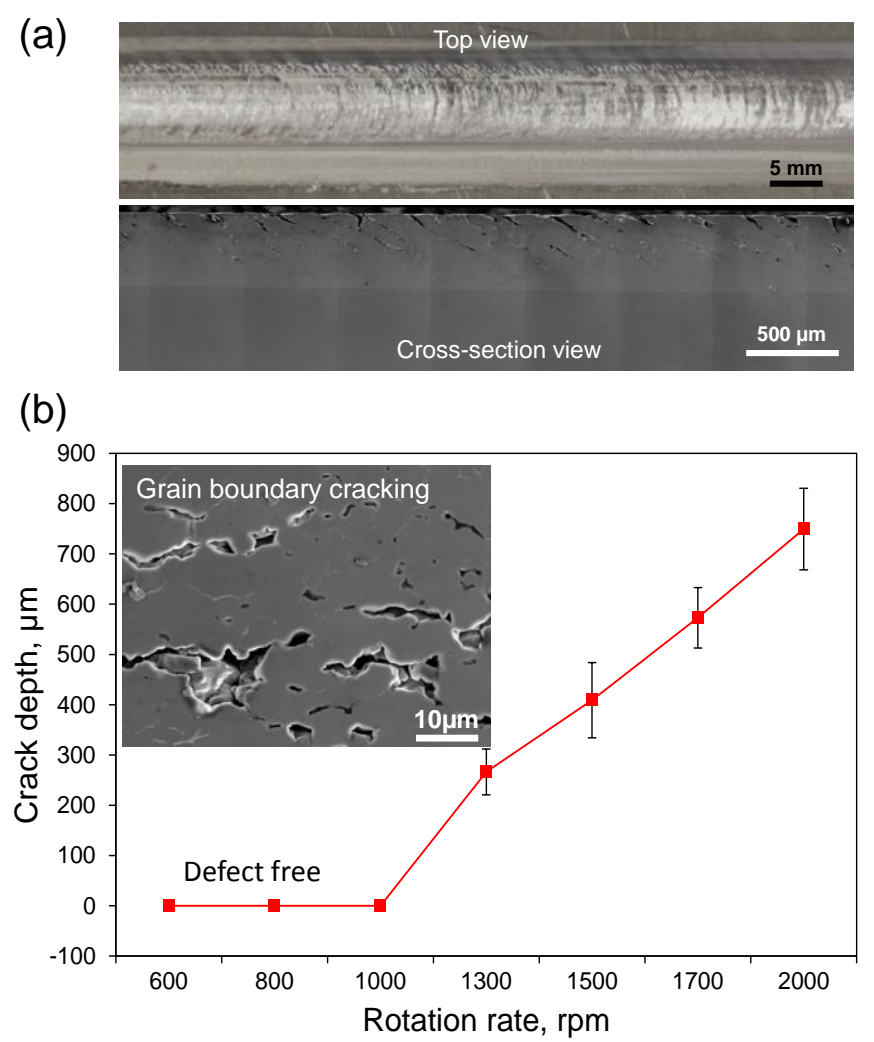

Fig. 7: Surface speed cracking seen in the SSFSW process; (a) images of the surface and near surface cross sections, through an overheated weld produced at $2000 \mathrm{rpm}$ and $400 \mathrm{~mm} \mathrm{~min}^{-1}$, (b) the effect of rotation rate on the crack depth at a travel speed of $400 \mathrm{~mm} / \mathrm{min}$, with an uncoated tool and an inset image showing liquation cracking along grain boundaries.

\section{Model Predictions}

Thermal modelling was used to systematically study the effect on a welds temperature field when moving from a FSW process, where the majority of the heat is generated by the tool shoulder, to SSFSW where all the energy is produced almost entirely by the probe. This was investigated by starting from a thermal simulation fitted to the conventional FSW process, for the optimum condition of $700 \mathrm{rpm}$ and $400 \mathrm{~mm} \mathrm{~min}^{-1}$, and then progressively reducing the shoulder power to zero. Results from these simulations are shown in Fig. 8 for two scenarios; i) where the shoulder power was reduced while maintaining a constant probe power, and ii) where the probe power was increased as the shoulder power was reduced to maintain the same temperature of $450^{\circ} \mathrm{C}$ at the base of the weld; as would be the case if the tool rotation rate was increased to compensate for the loss of heat generated by the shoulder. It can be seen from Fig. 8 that the results of these simulations agree 
well with the trends reported for the hardness maps shown in Fig. 3. For both scenarios, when the heat input contribution from the shoulder is reduced, the thermal field becomes narrower and more parallel through the plate thickness. However, it is evident that if the probe power is kept constant while the shoulder power is decreased the welds rapidly become too cold and this would lead to a breakdown in the welding process and failure of the tool. For the second scenario, it can be seen that if the probe power is increased to compensate for the loss of the heat input from the shoulder (i.e. by increasing the probe rotation rate), the thermal field still stays more uniform through the plate thickness. In addition, in agreement with discussion above concerning the optimum welding conditions identified for each process, for scenario II the total power input used in the probe only simulation of $1300 \mathrm{~W}$ was about $40 \%$ less than that for the FSW process, which required a shoulder power of 1,800 and a probe power of $500 \mathrm{~W}$ to fit the temperature measurements.

(a)

(b)

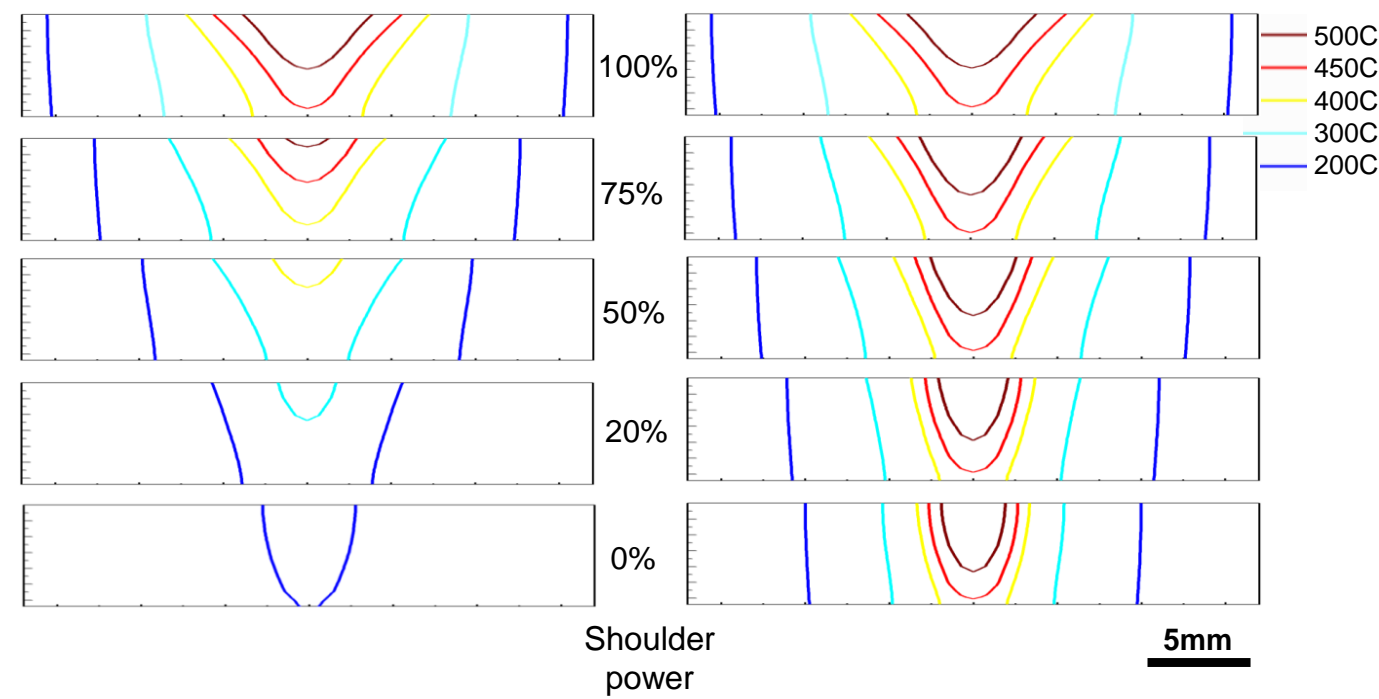

Fig. 8: Thermal modelling showing the response of the weld temperature field to progressively reducing the shoulder heat input from that required for the FSW simulation to zero, as would be the case in SSFSW; (a) with a constant probe power and (b) with the probe power increased to maintain a $450^{\circ} \mathrm{C}$ temperature at the base of the weld (at a travel speed of $400 \mathrm{~mm} / \mathrm{min}$ ).

The temperature histories calculated at different positions by the thermal simulations have also been used as input to the hardness model, to predict the effect on the HAZ depth and width when the shoulder power is reduced. For these predictions the second more realistic scenario was adopted, where the probe power was increased to compensate for the loss of the shoulder heat input by maintaining a $450{ }^{\circ} \mathrm{C}$ temperature at the weld base. Examples of the resultant hardness profiles predicted across the mid plate thickness are shown in Fig. 9a, as a function of distance from the 
weld centreline, for the standard FSW weld and with the shoulder heat input reduced by $50 \%$ and to zero, as would be the case in a SSFSW. In Fig. 9a the hardness measurements for the equivalent standard FSW weld are also shown for comparison with the model predictions, which can be seen to give reasonable agreement, except in the nugget region where there is an additional strengthening contribution from the high level of grain size refinement (this is equivalent to an additional hardness increment of approximately $10 \mathrm{Hv}$ ). In addition, in Fig. 9b the predicted HAZ width (defined as the distance from the weld centreline to reach parent properties) and the predicted hardness minima level at the plate mid plane are plotted against reduction in shoulder power. Overall, these results show good agreement with the hardness profiles in Fig. 4. For example, in Fig.9b it can be seen that, despite the probe power being increased to prevent the base of the welds becoming too cold, the HAZ is still predicted to reduce by approximately $40 \%$ in width and the minimum hardness level to increase by about $5 \mathrm{Hv}$ when the shoulder heat input is reduced to zero, to replicate stationary shoulder welding.

(a)

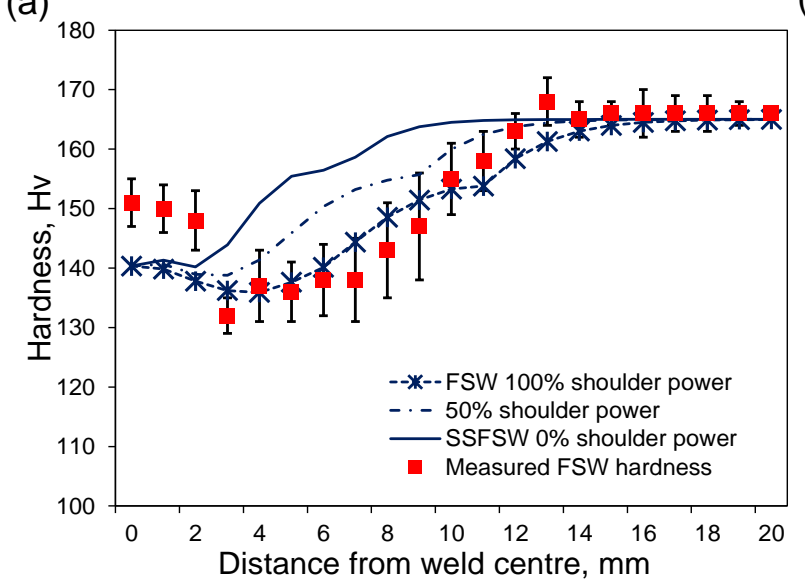

(b)

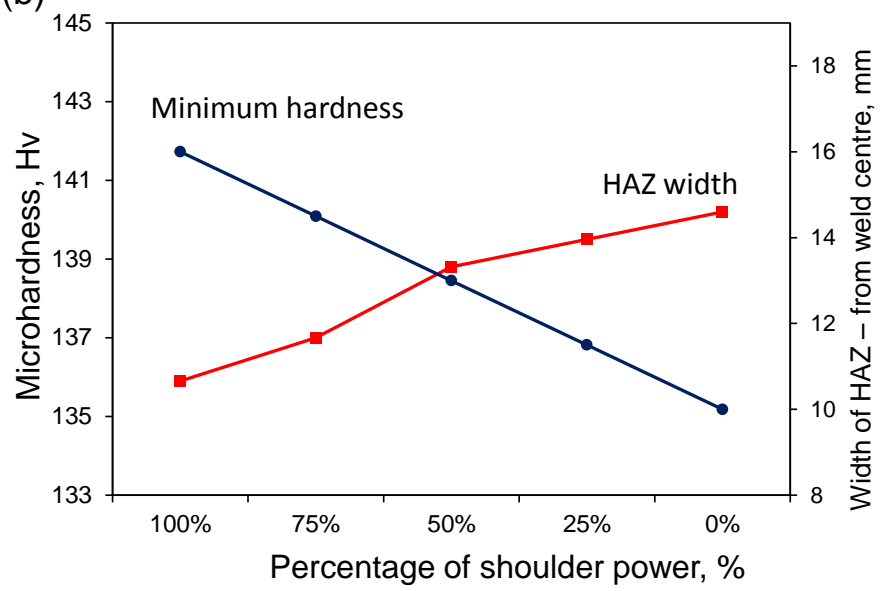

Fig. 9: Hardness predictions for the optimised FSW weld and on reducing the shoulder heat input while the probe power was increased to maintain a $450^{\circ} \mathrm{C}$ temperature at the weld base showing; (a) half width profiles and (b) the effect on the HAZ width and hardness minimum (all at mid thickness). In (a) the predictions are compared to hardness measurements made for the conventional FSW case.

\section{Comparison of the Welds Tensile Behaviour}

Cross-weld tensile tests were performed to compare the effect of the different weld zone hardness profiles, discussed above, on the mechanical properties of welds produced by the FSW and SSFSW processes. Because it was not possible to weld with the same conditions, a direct comparison was therefore made with welds produced using the optimum parameters previously determined of 1500 
for SSFSW and $700 \mathrm{rpm}$ for FSW, at a travel speed of $400 \mathrm{~mm} \mathrm{~min}^{-1}$. Tensile test results were also obtained for the same conditions used in Fig. 4, by fixing the rotation rates and reducing the travel speed.

When tensile testing friction stir welds in high strength aluminium alloys that do not contain defects, yielding generally first initiates at the weld hardness minima positions (Fig. 4), which are in the region of the boundary between the HAZ and TMAZ (as reported by Threadgill et al., 2009). Due to the high concentration of strain that normally takes place in this region failure occurs in the same location and the overall failure strain, when measured from the average elongation across the gauge length, is generally relatively low compared to that of the parent material (Mahoney et al., 1998). Examples of the failure position of the welds studied are provided in Fig. 10b and this always occurred in their HAZs at a location consistent with the hardness minima positions in the profiles shown in Fig. 4. The weld's average tensile properties are plotted in Fig. 10 against travel speed and are summarised in Table 1 for the optimum welding conditions. As anticipated, with increasing travel speed the strength and ductility improved for welds produced with both processes, because this reduced the width and decrease in hardness at the minima positions in the HAZ, as can be seen in Fig. 4 and was predicted in Fig. 9b. From Fig. 10 it can be seen that there was not a large difference in the average cross-weld tensile properties measured for the two processes, but at a given travel speed the proof stress, tensile strength, and strain to failure all tended to be greater for the welds produced with the stationary shoulder process. Furthermore, in Table 1 it can be noted that with optimum welding conditions the average tensile strengths achieved by the FSW and SSFSW processes were $88 \%$ and $92 \%$ of the parent material properties, respectively.

\begin{tabular}{lccc} 
& FSW & SSFSW & Parent \\
& $\left(700 \mathrm{rpm} 400 \mathrm{~mm} \mathrm{~min}^{-1}\right)$ & $\left(1500 \mathrm{rpm} 400 \mathrm{~mm} \mathrm{~min}^{-1}\right)$ & AA7050-T7651 \\
\hline Proof Stress & $382 \mathrm{MPa}$ & $410 \mathrm{MPa}$ & $490 \mathrm{MPa}$ \\
Tensile Strength & $486 \mathrm{MPa}$ & $505 \mathrm{MPa}$ & $552 \mathrm{MPa}$ \\
Failure Elongation & $6.1 \%$ & $6.3 \%$ & $11 \%$
\end{tabular}

Table 1: Average cross-weld tensile properties of samples produced by FSW and SSFSW under optimised welding conditions compared to that of the parent plate. 
(a)

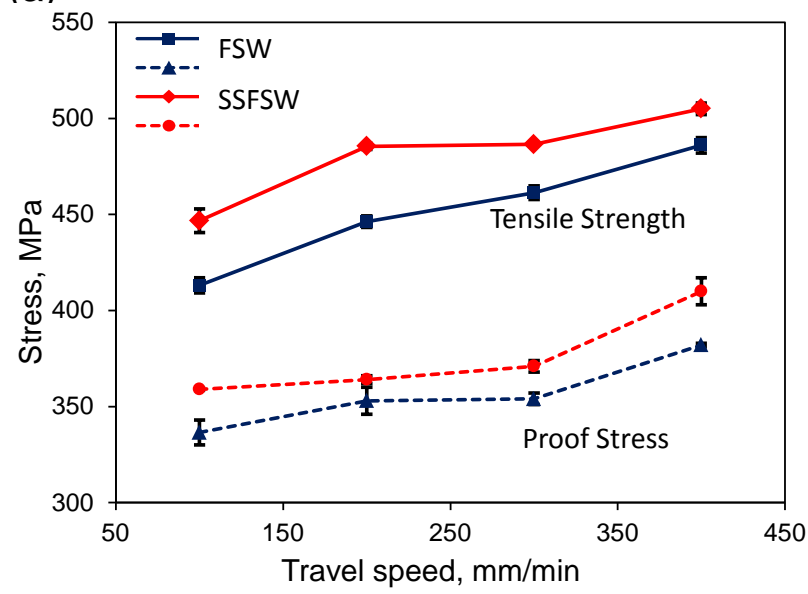

(b)

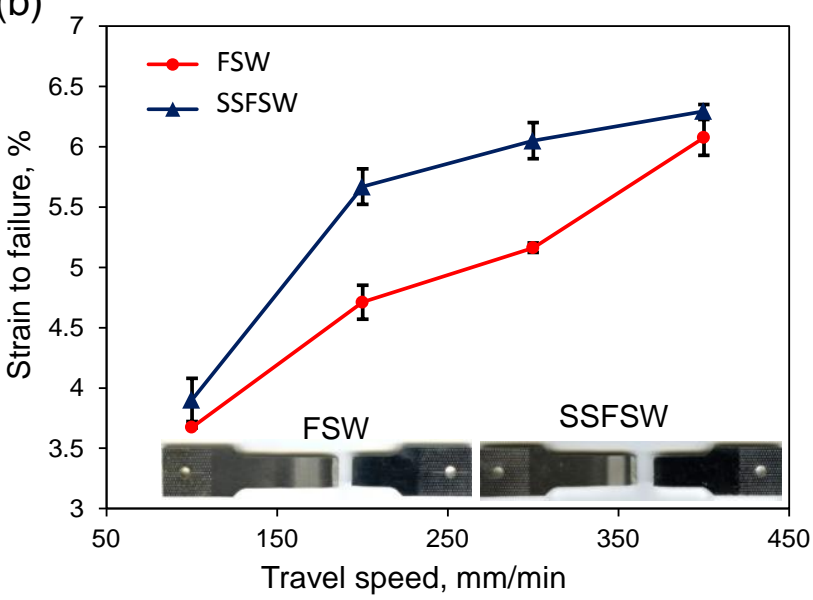

Fig. 10: Results from cross weld tensile tests performed on FSW and SSFSW welds showing; (a) the average proof stress and tensile strength and (b) strain to failure, as a function of travel speed, with rotation rates of $700 \mathrm{rpm}$ and $1500 \mathrm{rpm}$ for the FSW and SSFSW processes, respectively. The images in (b) show the failure positons.

(a)

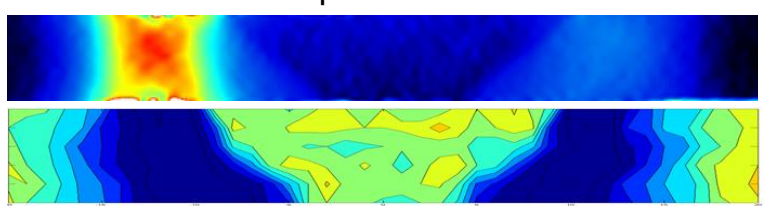

FSW $700 \mathrm{rpm} 400 \mathrm{~mm} / \mathrm{min}$

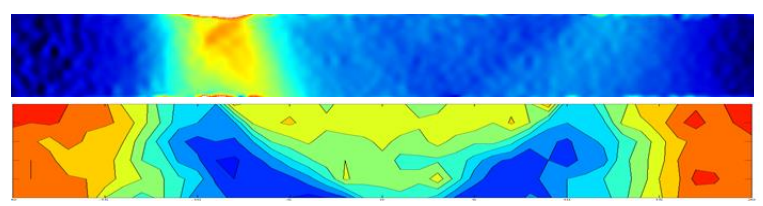

$$
\varepsilon_{\mathrm{yy}, \%}
$$

Hardness, $\mathrm{H}_{\mathrm{V}} 120$ (b)

SSFSW $1500 \mathrm{rpm} 100 \mathrm{~mm} / \mathrm{min}$

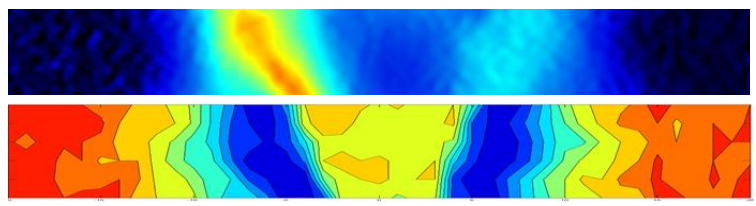

SSFSW $1500 \mathrm{rpm} 400 \mathrm{~mm} / \mathrm{min}$

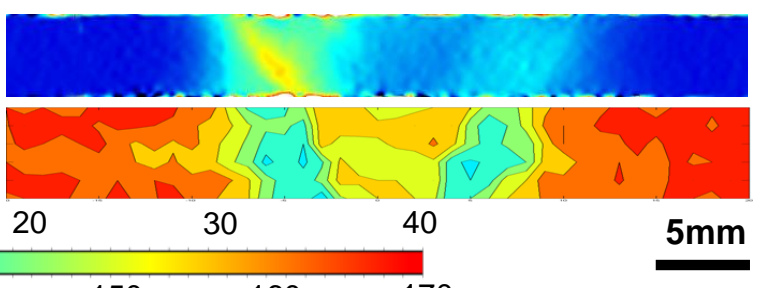

Fig. 11: Digital image correlation (DIC) local strain $\left(\varepsilon_{\mathrm{yy}}\right)$ maps from cross-weld tensile tests (above), just before the point of failure, compared to corresponding weld cross section hardness maps prior to testing (below; in each paired image), for welds produced by (a) FSW and (b) SSFSW at 700 and $1500 \mathrm{rpm}$, respectively, with travel speeds of 400 and $100 \mathrm{~mm} \mathrm{~min}^{-1}$.

To better understand why welding with a stationary shoulder leads to an improvement in the tensile performance of FSW joints, additional tensile tests were performed while using digital image correlation (DIC) strain mapping to measure the strain distribution across the weld zones. This was performed on the polished edge of the samples in order to view the local plastic strain distribution as it developed across the weld cross sections. In Fig. 11 DIC maps near the point of fracture are 
compared to the corresponding hardness distributions in each weld prior to testing, for joints produced with the high optimum $\left(400 \mathrm{~mm} \mathrm{~min}^{-1}\right)$ and lower $\left(100 \mathrm{~mm} \mathrm{~min}^{-1}\right)$ travel speeds; examples of the progressive development of the local strain profile with increasing macroscopic sample strain are also plotted in Fig. 12, for the $100 \mathrm{~mm} \mathrm{~min}^{-1}$ welds.

(a)

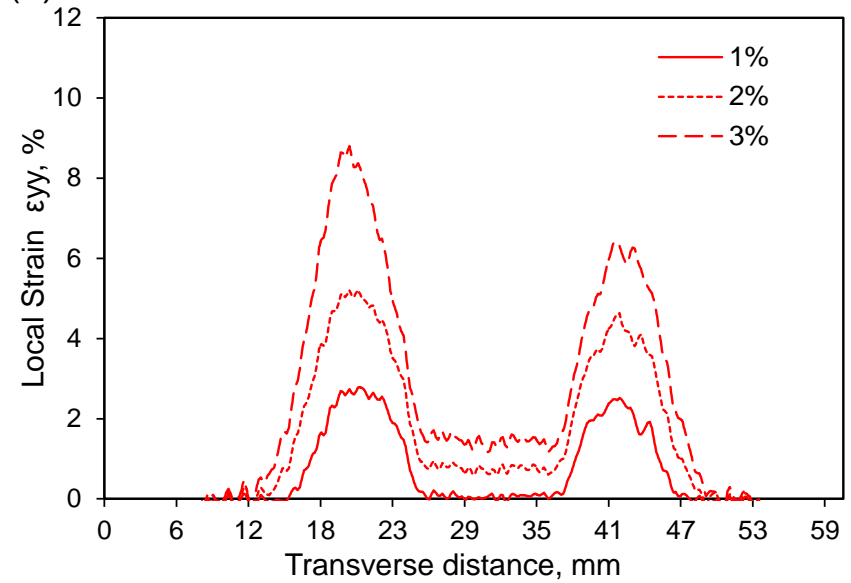

(b)

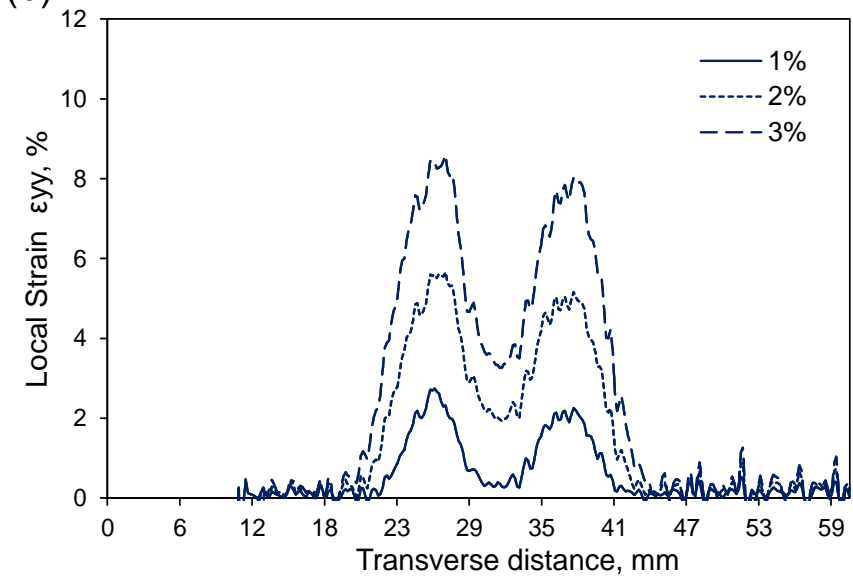

Fig. 12: Progressive development of the local strain $\left(\varepsilon_{\mathrm{yy}}\right)$ across the weld mid-plane during tensile testing, obtained by digital image correlation (DIC); (a) FSW at $700 \mathrm{rpm}$, and (b) SSFSW at 1500 rpm with a travel speed of $100 \mathrm{~mm} \mathrm{~min}^{-1}$.

In each weld it can be seen that strain is concentrated in the soft band that corresponds with the minima positions in the hardness profiles. From this data it is also apparent that, when compared at the same macroscopic strain level of 3\% (Fig. 12), the maximum local strain is slightly lower in the HAZ of the stationary shoulder welds than in the conventional friction stir welds, where it is also more dispersed within the weld nugget zone. In contrast, in the standard friction stir welded samples deformation is more localised in the two HAZ minima positions. This is principally because the HAZ minima are slightly less deep, but also narrower in the equivalent stationary shoulder welds and the harder surrounding material can thus constrain deformation more. For example, in the DIC profiles in Fig. 12 it can be seen that the concentration of plastic strain within the HAZ/TMAZ boundary is initially sharper in the stationary shoulder weld samples. Furthermore, the slip pattern in the DIC maps can be seen to be different in the welds produced by the two processes. This is more obvious when comparing the welds that have larger HAZs that were produced at a lower travel speed. For example, in Fig. 11b in the stationary shoulder weld the deformation is localised in a narrow shear band tilted at $\sim 45^{\circ}$, whereas in comparison the wider HAZ produced by the FSW with a rotating shoulder has led to deformation occurring across a bigger area (Fig. 12a) that shows evidence of macroscopic shear at both + and $-45^{\circ}$ to the tensile axis. 


\section{Conclusions}

A stationary shoulder greatly reduced the power dissipated by the tool in FSW. As a result, the process windows for the SSFSW and traditional FSW method did not overlap and the rotation rate had to be doubled to maintain a sufficiently high weld temperature to avoid tool failures. A rational approach was therefore proposed for directly comparing the two processes, based on first determining their power-rotation rate curves and then selecting the optimum welding conditions. Using this approach, it was shown that stationary shoulder welding requires an approximately $30 \%$ lower heat input than conventional FSW.

Welding with a stationary shoulder produced welds with a narrower, more parallel, heat affected zone and lower through-thickness microstructure and property gradients. The welds performed better than conventional FSWs in cross-weld tensile tests. DIC analysis of the strain distribution in the test pieces revealed that this resulted from their narrower HAZ helping to prevent premature failure, by imposing greater constraint on the localisation of plastic strain during deformation.

Thermal simulation, combined with hardness modelling, confirmed that the above benefits arose from changing the FSW process from one, where the majority of heat is introduced by conduction into the workpiece from the energy dissipated by a rotating shoulder, to one where heat is generated more efficiently and uniformly through the plate thickness by only the probe.

The ironing effect of the stationary shoulder greatly reduced the weld's surface roughness. Furthermore, the colder surface temperature dramatically decreased the reduction in workpiece thickness normally seen along the weld line in the standard FSW process caused by the shoulder plunge.

A negative effect of welding with a stationary shoulder is that it can lead to 'speed cracking' similar to that found in extrusion under hotter welding conditions (e.g. with too high tool rotation rates, or when too high a travel speed is employed).

Acknowledgements: We are grateful for Dr J.D. Robson for assistance with the modelling work and financial support provided by EPSRC through LATEST2, (EP/G022402/1) and the Metallic Systems CDT (EP/G036950/1). 


\section{References}

Barbini, A., Carstensen, J., Miyazaki, M., Fernandez, dos Santos, F, J. , Huber, N., 2014. Comparison between the deformation behaviour of dissimilar AA2024-T3/AA7050-T7651 welds produced by stationary shoulder friction stir welding and standard friction stir welding. AEROMAT 2014, Orlando, Florida.

Colegrove, P.A., Shercliff, H.R., and Zettler, R., 2007. Model for predicting heat generation and temperature in friction stir welding from the material properties. Sci. Technol. Weld. Joining. 12, 284-297.

Cui, S., Chen, Z.W., Robson, J.D., 2010. A model relating tool torque and its associated power and specific energy to rotation and forward speeds during friction stir welding/processing. Int. J. Machine Tools Manuf. 50, 1023-1030.

Davies, P.S., Wynne, B.P., Rainforth, W.M., Thomas, M.J., Threadgill, P.L., 2011. Development of microstructure and crystallographic texture during stationary shoulder friction stir welding of Ti-6Al-4V. Metall. Mater. Trans. A, 42, 2278-2289.

Hassan, Kh. A.A., Prangnell, P.B., Norman, A.F., Price, D.A., Williams, S.W., 2003. Effect of welding parameters on nugget zone microstructure and properties in high strength aluminium alloy friction stir welds. Sci. Technol. Weld. Joining. 8, 257-268.

Johnsen, M. R., 1999. Friction stir welding takes off at Boeing. Weld. J. 78, 35-39.

Kamp, N., Sullivan, A., Tomasi, R., Robson, J.D., 2006. Modelling of heterogeneous precipitate distribution evolution during friction stir welding process. Acta Mater. 54, 2003-2014.

Li, J.Q., Liu, H.J., 2013. Effects of tool rotation speed on microstructures and mechanical properties of AA2219-T6 welded by the external non-rotational shoulder assisted friction stir welding. Mater. Design. 43, 299-306.

Liu, H. J., Li, J. Q., Duan, W. J., 2013. Friction stir welding characteristics of 2219-T6 aluminium alloy assisted by external non-rotational shoulder. Int. J. Adv. Manuf. Technol. 64, 1685-1694.

Long, T., Tang, W., Reynolds, A. P., 2007. Process response parameter relationships in aluminium alloy friction stir welds. Sci. Technol. Weld. Joining. 12, 311-337.

Mackwood, A.P., Crafer, R.C., 2005. Thermal modelling of laser welding and related processes: a literature review. Optics Laser Technol. 37, 99-115. 
Mahoney, M.W., Rhodes, C.G., Flintoff, J.G., Spurling, R.A., Bingel, W.H., 1998. Properties of friction-stir-welded 7075 T651 aluminum. Metal. Mater. Trans. A 29A, 1955-1964.

Martin, J. P., Stanhope, C., Gascoyne, S., 2011. Novel techniques for corner joints using friction stir welding. Proceedings of FSW symposium, TMS 2011 Annual Meeting, 179-186.

Neto, D. M., Neto, P., 2013. Numerical modelling of friction stir welding process: a literature review. Int J. Adv. Manuf. Technol. 65, 115-126.

Peng, Z., Sheppard, T., 2004. Study of surface cracking during extrusion of aluminium alloy AA 2014. Mater. Sci. Technol. 20, 1179-1191.

Prangnell, P. B., Heason, C.P., 2005. Grain Structure Formation During Friction Stir Welding Observed by the 'Stop Action Technique'. Acta Mater. 53, 3179-3192.

Rai, R., De, A., Bhadeshia, H. K. D. H., DebRoy, T., 2011. Review: friction stir welding tools. Sci. Technol. Weld Joining. 16, 325-342.

Richards, D. G., Prangnell, P. B., Williams, S.W., Withers, P.J., 2008. Global mechanical tensioning for the management of residual stresses in welds. Mater. Sci. Eng. A. 489, 351-362.

Richards, D. G., Prangnell, P. B., Withers, P. J., Williams, S. W, Nagy, T. Morgan, S., 2010. Efficacy of active cooling for controlling residual stresses in friction stir welds, Sci. Tech. Weld. Joining. 15, 156-165.

Robson, J.D., Sullivan, A., 2006. Process model for strength of age hardenable aluminium alloy welds. Mater. Sci. Technol. 22, 146-152.

Russell, M.J., Nunn, M.E., Martin, J., 2008. Recent developments in the stationary shoulder FSW of titanium alloys , Proceedings of 7th Int. Symp. on Friction Stir Welding, Japan, TWI, 2008.

Schmidt, H., Hattel, J., West, J., 2004. An analytical model for the heat generation in friction stir welding, Modelling and Simulation. Mater. Sci. Eng. 12, 143-157.

Shercliff, H.R., Ashby, M.F., 1990. A process model for age-hardening aluminium alloys: Part I: The model. Acta Metall. Mater. 38, 1789-1802.

Sullivan, A., Robson, J.D., 2008. Microstructural properties of friction stir welded and post-weld heat-treated 7449 aluminium alloy thick plate. Mater. Sci. \& Eng. A. 478, 351-360. 
Thomas, W. M., Nicholas, E. D., Needham, J. C., Murch, M. G., Temple-Smith, P., Dawes, C. J., 1991. Improvements relating to friction welding. GB patent no. 9125978-8.

Threadgill, P. L., Leonard, A. J., Shercliff, H. R., Withers, P. J., 2009. Friction stir welding of aluminium alloys. Int. Materials Reviews. 54, 49-93.

Widener, C.A., Talia, J.E., Tweedy, B.M., Burford, D.A., 2006. High-rotational speed friction stir welding with a fixed shoulder. 6th Int. Symp. on Friction Stir Welding, Canada.

Williams, S.W., Colegrove, P.A., Shercliff, H., Prangnell, P., Robson, J.D., Withers, P.J. Richards, D., Sullivan, A., Kamp, N., Lohwasser, D ., Poad, M., 2006. Integrated Modelling of the Friction Stir Welding Process. Proceedings of $6^{\text {th }}$ Friction Stir Welding Symposium, Canada., TWI, 2006.

\section{Figure Captions}

Fig. 1: Schematic diagrams of (a) the FSW and (b) the SSFSW tools used in this investigation with their dimensions.

Fig. 2: (a) Measured and fitted torque - rotation rate curves and (b) the corresponding power curves derived for both process variants, following the method detailed in the text. In (b) the approximate upper and lower process boundaries are shown as short dashed curves.

Fig. 3: Weld cross-sections and corresponding hardness contour maps from welds produced by both processes at comparable optimum rotation rates with increasing travel speed, (a) a FSW at $700 \mathrm{rpm}$ and (b) SSFSW at 1,500 rpm, measured after two months post-weld natural ageing. 
Fig. 4: Mid-plane hardness profiles obtained from welds produced with increasing travel speeds at optimum rotation rates; (a) a FSW tool at $700 \mathrm{rpm}$ and (b) a SSFSW tool at 1,500 rpm, measured after post-weld natural ageing for two months.

Fig. 5: Typical through-thickness (a) grain size and (b) hardness levels, seen for the FSW and SSFSW processes, plotted down the centre of a weld nugget, from welds produced under optimum conditions of $700 \mathrm{rpm}$ and $1500 \mathrm{rpm}$, at $400 \mathrm{~mm} / \mathrm{min}$, respectively.

Fig. 6: Comparison of the surface quality obtained with both processes; (a) and (b) surface displacement maps for FSW and SSFSW, respectively, (c) and (d) the surface roughness ( $\mathrm{Ra}$ ) and the local displacement relative to the original plate surface, measured across each weld track, for welds produced under optimum conditions (FSW $700 \mathrm{rpm}, 400 \mathrm{~mm} / \mathrm{min}$ and SSFSW $1500 \mathrm{rpm}, 400 \mathrm{~mm} \mathrm{~min}^{-1}$ ).

Fig. 7: Surface speed cracking seen in the SSFSW process; (a) images of the surface and near surface cross sections, through an overheated weld produced at $2000 \mathrm{rpm}$ and $400 \mathrm{~mm} \mathrm{~min}$ ${ }^{1}$, (b) the effect of rotation rate on the crack depth at a travel speed of $400 \mathrm{~mm} / \mathrm{min}$, with an uncoated tool and an inset image showing liquation cracking along grain boundaries.

Fig. 8: Thermal modelling showing the response of the weld temperature field to progressively reducing the shoulder heat input from that required for the FSW simulation to zero, as would be the case in SSFSW; (a) with a constant probe power and (b) with the probe power increased to maintain a $450^{\circ} \mathrm{C}$ temperature at the base of the weld (at a travel speed of 400 $\mathrm{mm} / \mathrm{min})$.

Fig. 9: Hardness predictions for the optimised FSW weld and on reducing the shoulder heat input while the probe power was increased to maintain a $450^{\circ} \mathrm{C}$ temperature at the weld base showing; (a) half width profiles and (b) the effect on the HAZ width and hardness minimum (all at mid thickness). In (a) the predictions are compared to hardness measurements made for the conventional FSW case.

Fig. 10: Results from cross weld tensile tests performed on FSW and SSFSW welds showing; (a) the average proof stress and tensile strength and (b) strain to failure, as a function of travel speed, with rotation rates of $700 \mathrm{rpm}$ and $1500 \mathrm{rpm}$ for the FSW and SSFSW processes, respectively. The images in (b) show the failure positon.

Fig. 11: Digital image correlation (DIC) local strain $\left(\varepsilon_{y y}\right)$ maps from cross-weld tensile tests (above), just before the point of failure, compared to corresponding weld cross section hardness maps prior to testing (below; in each paired image), for welds produced by (a) 
FSW and (b) SSFSW at 700 and 1500 rpm, respectively, with travel speeds of 400 and 100 $\mathrm{mm} \min ^{-1}$.

Fig. 12: Progressive development of the local strain $\left(\varepsilon_{\mathrm{yy}}\right)$ across the weld mid-plane during tensile testing, obtained by digital image correlation (DIC); (a) FSW at $700 \mathrm{rpm}$, and (b) SSFSW at $1500 \mathrm{rpm}$ with a travel speed of $100 \mathrm{~mm} \mathrm{~min}^{-1}$.

Table 1: Average cross-weld tensile properties of samples produced by FSW and SSFSW compared to that of the parent plate. 